\title{
The current situation and prospect of the management of anti- seismic protection of historical buildings
}

\author{
Pei LI ${ }^{1}$ \\ ${ }^{1}$ Business School, Shanghai Jianqiao University, Shanghai,China
}

\begin{abstract}
The seismic safety of historical buildings is one of the key and difficult points in the protection and utilization of historical buildings. This article introduces and analyzes the status quo of historical building seismic reinforcement technology from the aspects of historical building definition and protection principles, reinforcement principles, and reinforcement methods. Finally, the development direction of seismic reinforcement technology for historic buildings is summarized and prospected.
\end{abstract}

\section{Introduction}

China is an ancient civilization with a long history. From ancient times to the present, China has kept many historical buildings in its continuous development. These various historical buildings that have evolved continuously have rich historical significance and also reflect the characteristics of each era. From the period of the Republic of China, a large number of reinforced concrete frame structures began to appear in the world [1]. This kind of structure has a large space for use, and the layout of the building is more flexible. Compared with the wood structure, the concrete material has high durability and fire resistance [2].

Although the appearance of reinforced concrete frame structure buildings is relatively late, some early buildings have exceeded the normal service life range specified in the relevant codes, especially some buildings that do not meet the earthquake resistance levels specified in the existing seismic codes. Such historical buildings with reinforced concrete frames need to be reinforced and designed to make the buildings meet the normal conditions of use. Besides, the corresponding reinforcement design of historical buildings is also to restore the original obscure historical significance, so that these unique historical buildings survive and restore their original appearance, to better retain their historical value [3].

How to adopt appropriate reinforcement methods, and how to adopt appropriate reinforcement methods under the premise of the principle of "repair the old as the old" of historical buildings, to ensure the normal use of the building itself and their safety, is worthy of further study at present and discuss topics [4, 5]. This article mainly summarizes and summarizes the traditional seismic reinforcement methods of historical buildings with reinforced concrete frame structures. On this basis, a comparative analysis of the effects before and after reinforcement is made on the cases of historical buildings with frame structures and aims to maintain the original structure of the historical buildings. Discuss the contradiction between authenticity and reinforcement method, and put forward corresponding suggestions.

\section{Research background and methods}

\subsection{Principles of Protection of Historic Buildings}

When repairing and strengthening historical buildings, they should be different from ordinary buildings. While considering the safety and applicability of the reinforced structure of the building, it is also necessary to comply with the relevant principles of historical building protection and build based on these protection principles. To strengthen historical buildings. According to the "Charter of Athens" and "Charter of Venice", the principles that should be followed for the protection of historical buildings are (1) Principle of integrity: While protecting historical buildings, not only consider the historical buildings themselves but also integrate with the overall surrounding environment, so that the historical building is restored to its original integral appearance. (2) The principle of authenticity: Keep the original construction methods, structural methods, building materials, and other historical legacies of the building, and retain the traces of history. (3) Principle of reversibility When strengthening historical buildings, it should be considered that better methods of strengthening the structure will be found in the future, and the method should preferably be detachable to ensure that the new strengthening technology in the future can repair the structure again. (4) Principle of Necessity Pay attention to the usual maintenance and maintenance of historical buildings and reduce the number of reinforcements and repairs. (5) Principle of identifiable the technology, equipment, process, and materials used in the 
reinforcement process is distinguished from the original structure so that they can be quickly understood and improved in the subsequent reinforcement and transformation. (6) The principle of sustainability When strengthening and repairing historical buildings, fully consider green building materials and effectively use renewable energy-saving materials.

\subsection{An overview of seismic strengthening methods for concrete frame structures}

To improve the seismic load-bearing capacity of concrete frame structure members, enhance the structural deformation capacity and change the frame structure system, it is necessary to carry out seismic reinforcement of these concrete frame structures and choose appropriate reinforcement schemes according to the actual situation.

At present, the seismic reinforcement methods of reinforced concrete frame structure buildings specified in the Chinese Code for Seismic Reinforcement "Technical Specification for Reinforcement of Concrete Structures GB50367-2013" mainly include the following categories: Enlarged section reinforcement method, replacement concrete reinforcement method, external prestressed reinforcement method, Outsourcing section steel reinforcement method, pasted steel plate reinforcement method, pasted fiber composite material reinforcement method, prestressed carbon fiber composite board reinforcement method, additional fulcrum reinforcement method, pre-tensioned steel wire rope mesh-polymer mortar surface layer reinforcement method, winding wire reinforcement method, Bar planting technology, crack repair technology.

In addition to some commonly used reinforcement methods specified in the "Technical Specification for Reinforcement of Concrete Structures GB50367-2013", the "Technical Specification for Seismic Reinforcement of Buildings JGJ116-2009" provides additional methods for the reinforcement of multi-story and high-rise concrete buildings, including adding seismic Wall or wing wall, reinforced concrete sleeve reinforcement, additional support reinforcement, and infill wall reinforcement method.

\section{Anti-seismic and anti-seismic methods of Chinese traditional buildings}

Different from Western masonry structures, the traditional Chinese wooden structure adopts the "softness to overcome rigidity" thinking when resisting the impact of earthquakes. Through various ingenious measures, the goal is to minimize the impact. The price of this will minimize the powerful natural destructive power. Many ancient buildings in my country have successfully withstood the test of a major earthquake, such as the Guanyin Pavilion of Dule Temple in Jixian County of Tianjin and the Wooden Pagoda in Yingxian County of Shanxi, which have experienced many earthquakes for thousands of years and still stand proudly. The contemporary architectural design aims to withstand 9-degree earthquakes, and my country's traditional wood-structured buildings can meet this requirement, and the cost is far less than the "rigid" of the West, and people cannot help but admire the power of "soft".

Flexible frame structure: the wall does not collapse and the house does not collapse. The Chinese nation has not only wisely selected wood and other organic materials as the main structural materials since the beginning of civilization, but has also developed into the world's oldest, longest-lasting, and most technologically mature Structural system-flexible frame system. The development of wood structure technology in China, if only from the Hemudu site in Yuyao, Zhejiang, has a history of at least nearly 7,000 years. In contrast, the West has been adopting a loadbearing wall system for thousands of years. It was not until the Industrial Revolution and the development of modern science and technology that they realized the superiority of the frame structure and began to spread on a large scale. What is more interesting is that the framework system is still "to overcome the rigidity with rigidity." The traditional wooden structure in China has various advantages of the frame structure, such as the effect of "the wall collapses and the house does not collapse", but its flexible connection makes it quite flexible and a certain degree of self-recovery ability. In the Wenchuan earthquake, the walls of many cultural relics were damaged to varying degrees, but the main structure has not collapsed, which is a manifestation of the seismic resistance of this flexible frame structure.

Integral floating raft foundation, buckets, and tenon joints: the key to earthquake resistance, in ancient my country, buildings with complex planes were rarely constructed, and rectangles with a length-to-width ratio less than 2:1 were mainly used. The regular plane shape and structural layout are conducive to earthquake resistance. In traditional buildings, the one in the middle (beware of the room) is often the largest, and the secondary and tip spaces on both sides are sequentially reduced in surface width. This design is very conducive to resisting earthquake torque.

Ancient Chinese buildings are generally composed of platform foundations, beams, and roofs. In high-level buildings, there is also a ditch layer between the roof and the beams. The foundations of ancient Chinese buildings are described in modern structural language. They can be called "integral floating raft foundations". It is like a large ship carrying the building floating in the "stormy waves" formed by the earthquake, which can effectively prevent the foundation of the building from being cut. Destroy, reduce the impact of seismic waves on the upper building. The beam frame of traditional Chinese buildings generally adopts a beam-lifting structure. In the vertical direction of the frame, a large and small structure is formed. The practice has proved that this construction method has good seismic performance. The elegant large roof is one of the most prominent image characteristics of ancient Chinese traditional buildings, and it has also made considerable contributions to improving the earthquake resistance of the building. The formation of a large roof (especially the top of the palace, the top of Xieshan, etc.) requires complex structures and a large number of components, which greatly increases the integrity of the roof and the entire 
structure; the huge roof presses on the column net with its weight, which also improves the stability of the structure.

Dougong is another important warrior in the antiseismic of ancient Chinese buildings. During an earthquake, it acts as a shock absorber of a car to deform and dissipate energy. Historically, many buildings with Doutong were able to withstand strong earthquakes, such as the Huayan Temple in Datong, Shanxi. The main hall with Doutong survived without the destruction of the lowlevel annexes of Doutong. This fully illustrates the contribution of Doutong to the earthquake. Dougong can play the role of a "shock absorber", and the Dougong group connected by various horizontal members can form a very integrated "rigid plate", which can reduce earthquakes in accordance with the principle of "those who can do more". The force is transmitted to the columns with seismic capacity, which greatly improves the safety of the entire structure.

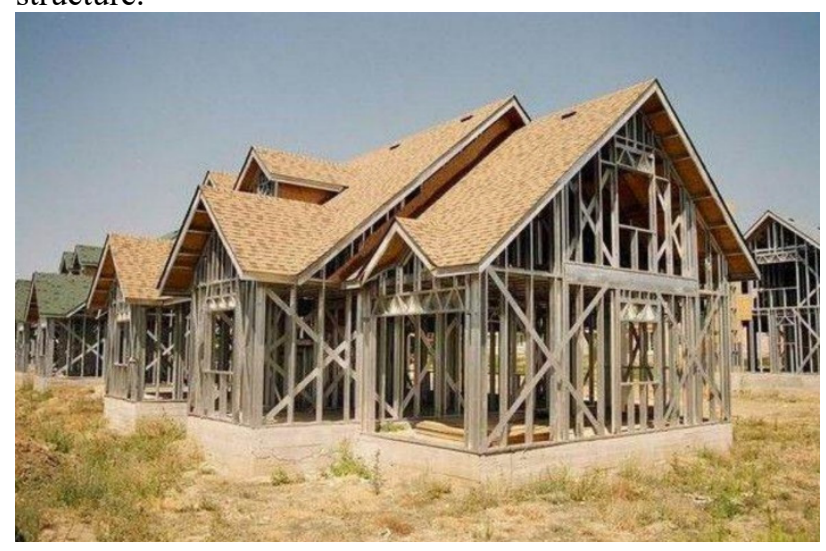

Fig1. The structure of the historical building

\section{Case Study}

Historical buildings are precious to the culture and history of a country. They are rare and non-renewable resources that reflect the architectural features and cultural values of a country in various eras. However, as the times change, most of them are "old" stage, and these buildings are subject to the test of durability and applicability. Besides, the seismic fortification of some such buildings was not considered or considered insufficiently. Therefore, appropriate methods need to be adopted for reinforcement. Reinforced concrete frame structure historical building is often used in various parts of the seismic reinforcement method. Therefore, the commonly used reinforcement method for the foundation part of the reinforced concrete frame structure historical building is mainly the root pile reinforcement technology, and the pillars and beams of the historical building are mainly reinforced by most methods. It is the enlarged section method, the outer steel reinforcement method, and the carbon fiber reinforcement method.

\subsection{Overview of the case of Shanghai historic buildings using the enlarged cross-section reinforcement method}

Shanghai Yangtze Hotel: There is a certain degree of damage, which affects the normal use of the building structure. Therefore, the owner of the building carried out a large-scale renovation and renovation of the Yangtze Hotel in 2007, and the building structure was appraised for earthquake resistance. According to the results of the seismic appraisal test, suitable reinforcement methods were adopted for the columns and beams of the historic building. Reconstruction and reinforcement were carried out, and the method of enlarged cross-section and carbon fiber reinforcement was adopted for the column.

Combining the above-mentioned reinforcement method of the enlarged section method and the "reversibility" and "authenticity" in the protection principle of historical buildings, there is a contradiction between the method of enlarged section used in the column in the present case for analysis. In this case, the degree of influence on the appearance of the building is different for the enlarged cross-section of the column in different spatial positions. The columns that do not affect the appearance of the building are reinforced with foursided concrete enclosures, that is, the areas of all four sections are increased. The side columns that affect the appearance of the building are reinforced with three-sided enclosures and single-sided enclosures, and the diagonal columns are reinforced with double-sided enclosures.

Shanghai Bund Yuan Lanxin Building: The building was renovated and strengthened in 2009, and the columns, beams, and walls were strengthened accordingly. Among them, an enlarged section reinforcement method is adopted for the west side column of the house, which solves the structural safety problems of insufficient frame column section size, excessive axial compression ratio, and insufficient longitudinal steel reinforcement in the original structure. The function of the building has changed from the Lanxin Theater before the renovation to a commercial building integrating commercial retail, office, and catering.

Shanghai Bund Yuan Zhongshi Building: The original function of the building was a bank office building. The building was renovated and reinforced in 2007. After the renovation, it became a commercial building integrating commerce, office buildings, and restaurants. According to the characteristics of the building structure, suitable reinforcement methods are adopted for different components. During the reinforcement process, the column reinforcement method is also adopted to increase the cross-section method. After adopting this reinforcement method, the durability of the reinforced column is effectively guaranteed, the bearing capacity and ductility of the members are greatly improved, and the reinforcement effect is obvious.

\subsection{Case analysis and evaluation}

In the above three historical building cases, the enlarged section method was adopted for the reinforcement of the columns, and there are certain similarities in the reinforcement methods. Aiming at the contradiction between the protection principle of historical buildings and the reinforcement method, the above three cases are evaluated and analyzed from the three aspects of the purpose of reinforcement, the use function conversion 
before and after the reinforcement of the building structure, and the significance of the reinforcement of historical buildings.

1) The relationship between the purpose of historical building reinforcement and the principle of protection: The main purpose of the reinforcement of the three cases of Shanghai Yangtze Hotel, Bund Yuan Lanxin Building, and Zhongshi Building is to improve the bearing capacity of the building structure and improve the seismic capacity of the house. The use of an enlarged cross-section reinforcement method can not only effectively improve the bearing capacity of the frame column, but also the overall rigidity of the structure. Therefore, in terms of the purpose of reinforcement of historical buildings, the reinforcement of the above-mentioned reinforced concrete frame structure of historical buildings is based on the principle of protection for the reconstruction and reuse of buildings, rather than purely for the protection of historical buildings. . For example, in the above cases, when the reinforcement method of increasing the cross-section is adopted, it is ensured that the shape of the pillars exposed to the outside of the building structure does not change, but the cross-section of the part in the internal space of the structure is increased, thus ensuring the original building The appearance always remains the same. Although the internal spatial structure of the building has slightly changed, it has not changed compared to the overall structural system, architectural style, and building facade. Therefore, from the perspective of the "authenticity" of the protection principle of historical buildings, the appearance of the building satisfies the requirements of "authenticity" to keep the appearance and structure of the building unchanged.

2) Analysis of the necessity of reinforcement: Because some historical buildings themselves have exceeded the originally stipulated seismic service life, the buildings built at that time did not meet the conditions specified in the existing seismic codes. Therefore, the seismic capacity of historical buildings cannot meet the requirements of normal use. Seismic reinforcement of them is necessary, after the seismic reinforcement of the historic building, the seismic capacity of the historic building will meet the requirements.

3) Seismic analysis before and after reinforcement of historic buildings: Combining the above three cases of seismic reinforcement of historical buildings in Shanghai, the seismic analysis before and after seismic reinforcement of historical buildings shows that increasing the cross-section reinforcement method can effectively improve the displacement angle between floors under earthquake action and adjust the original noncompliance with the code requirements. The axial compression ratio of the structural column, so that the axial compression ratio of the structural column is appropriately reduced. At the same time, adopting the method of increasing the cross-section can more reliably improve the reinforcement of the frame column and the cross-sectional size.

\subsection{Feasibility analysis of increasing section method in seismic reinforcement of historic buildings}

The structural integrity of modern reinforced concrete historical buildings is relatively intact, so they have become the main target of seismic reinforcement and utilization. According to the results of the case analysis, the purpose of the reconstruction and utilization of the reinforced concrete historic buildings at this stage is greater than its historical value, so the space changes brought about by the reinforcement are relatively free. The above three cases can all be attributed to the reuse of historical buildings after protection. That is to say, it is required that the appearance of the historical building structure is roughly unchanged, and the internal use function layout can be changed to a certain extent. Therefore, for the modern reinforced concrete historical buildings, the main purpose is to protect and reuse the historical buildings. It is also feasible to use the method of increasing the cross-section for reinforcement without destroying the appearance of the building.

\section{Conclusion}

This article focuses on the relevant protection principles of historical buildings, and at the same time summarizes the reinforcement methods of reinforced concrete structures. It also lists the reinforcement cases of such historical buildings in recent years. Through a comparative analysis of the cases before and after reinforcement, the following points are summarized:

(1) At present, many achievements have been made in the reinforcement and reconstruction of historical buildings in China, and the relevant seismic reinforcement methods stipulated in the corresponding codes are becoming more and more perfect.

(2) Reinforcement methods for historical buildings should be based on general structural reinforcement methods, based on the premise of following the principles of historical building protection. Especially when using reinforcement methods, consideration should also be given to the "reality" involved in the principles of historical building protection. The principle of "sexuality" and "reversibility" was implemented and verified.

(3) At the same time of reinforcement, the historical value of the historic building and the purpose of reuse after the protection of the building should be appropriately weighted, combined with the actual engineering situation, and relevant choices should be made according to the principles and characteristics of historic building protection a certain reinforcement scheme cannot be selected blindly.

\section{Acknowledgment}

Research Project of Shanghai Jianqiao University "Research on Restoration and Reuse of Historical Buildings Based on BIM Technology" (No.SJQ17016) 


\section{References}

1. Bertagnoli, Gabriele, et al. "Reinforced Concrete Frame Structures is ." Procedia Engineering 161(2016):1013-1017.

2. P.C Aïtcin. "The durability characteristics of high performance concrete: a review." Cement \& Concrete Composites 25.4(2003):409-420.

3. Martelli, Alessandro. "Development and application of innovative anti-seismic systems for the seismic protection of cultural heritage." Federico M. Mazzolani (2009):págs. 43-52.

4. Indirli, Maurizio, et al. "Development and Application of Innovative Anti-Seismic Systems for the Protection of Cultural Heritage: New Achievements of ENEA." 2002 ASME-Pressure Vessel and Piping Conference, 14th International Symposium on Seismic, Shock and Vibration Isolation 2002.

5. Ionescu, Adriana, et al. "Software Program for Two Levers Damper Configurations Used for AntiSeismic Protection of the Buildings during Seism." Applied Mechanics and Materials 896(2020):347-354 . 